\title{
La explotación en el «área social», Una lectura de la precariedad laboral del tercer sector en Chile desde El capital de Marx*
}

\author{
Exploitation in the «social area». A reading of labor precariousness of the \\ third sector in Chile from Marx's Capital
}

\author{
Alejandro Varas*, Aníbal Carrasco**, Diego Gutiérrez ${ }^{* * *}$, Alejandra Bascuñán****
}

\begin{abstract}
Resumen: El siguiente artículo analiza la actual precariedad laboral en el área social en Chile desde El capital de Karl Marx. Este análisis busca comprender las relaciones existentes entre Estado, privados y clase trabajadora en el financiamiento y ejecución de la política social. Para dar cuenta de los modos de «explotación», se examinan los conceptos de «salario por tiempo» y «salario a destajo», así también se analiza la lógica del 'lucro', entendida ésta como acumulación capitalista en el 'sistema de licitaciones'.
\end{abstract}

Palabras clave. área social; precariedad; Chile; explotación; El Capital; Karl Marx.

\begin{abstract}
The following article analyzes the current labor precariousness in the social area in Chile from Karl Marx's Capital. This analysis seeks to comprehend the existent connections between the State, private organisms and the working class in the financing and execution of the social policy. To account for the types of 'exploitation', the concepts of 'time wage" and 'piece wage' are examined; also, the logic of 'profit' is analyzed, which is understood as capitalist accumulation in the 'bidding system'.
\end{abstract}

Key words: third sector; labor precariousness; Chile; exploitation; Capital; Karl Marx.

\footnotetext{
* Este texto fue escrito en el contexto del Taller de lectura "El capital de Karl Marx", coordinado por La Cimarra, proyecto colectivo de autogestión educativa. Además, se nutre de variadas reflexiones y experiencias enmarcadas en la Coordinadora Interregional de Trabajadorxs del Área Social (CITAS).

* Chileno, autor principal. Psicólogo y Mg. en Filosofía. Trabaja actualmente en la Universidad de Playa Ancha de Ciencias de la Educación. Participa en la Coordinadora Interregional de Trabajadorxs del Área Social (CITAS) y en el "Taller de lectura de El capital de Karl Marx" de La Cimarra'. Email: alejandro.v.alvarado@gmail.com

** Aníbal Carrasco, chileno, autor secundario. Psicólogo y Estudiante Tesista del Magíster en Literatura por la Pontificia Universidad Católica de Valparaíso. Trabaja actualmente en el Espacio Cultural Casa Yafün, ubicado en Valparaíso, y participa en el "Taller de lectura de El capital de Karl Marx" de La Cimarra. Email: anibal_acr@hotmail.com

**** Chileno, autor secundario. Estudiante Tesista de la Carrera de Historia de la Universidad de Playa Ancha de Ciencias de la Educación. Trabaja actualmente en el Comité Cultural y Deportivo El Volante, ubicado en Cerro Placeres, Valparaíso; y participa en el "Taller de lectura de El capital de Karl Marx" de La Cimarra. Email: diego.g.aguilera@ hotmail.com

***** Chilena, autora secundaria. Administradora Turístico Cultural de la Universidad de Valparaíso. Es integrante de la Escuela y Compañía de Danza del Vientre Tribal Tribu Sumpai Zugun, trabaja en el Centro Cultural Casa Yafün ubicado en Valparaíso, y participa en el "Taller de lectura de El capital de Karl Marx" de La Cimarra. Email: ale.bascunanh@gmail.com
} 


\section{Introducción: el área social en Chile y su precariedad laboral}

Cuatro décadas son las que han transcurrido en Chile desde la imposición, consolidación y perfeccionamiento del modelo neoliberal en nuestro país, lo cual ha implicado transformaciones en las lógicas del trabajo y múltiples efectos en quienes protagonizan o están vinculados a estos procesos ${ }^{2}$. Uno de los ámbitos laborales afectados ha sido el denominado «tercer sector» ${ }^{3} \mathrm{o}$ «área social» $»^{4}$, sector que se define por ser aquel que ejecuta la política social del Estado, siendo aquella la que se vincula más estrechamente al trabajo con sectores socialmente marginados y excluidos ${ }^{5}$. Una de las transformaciones más expresivas en este sector es, a partir de los años 90, la inserción de organismos externos al aparato estatal, que tienen por objetivo implementar las políticas sociales ${ }^{6}$. A estas entidades las denominaremos, desde ahora en adelante, OSFL (Organizaciones Sin Fines de Lucro) ${ }^{7}$.

Con la inserción de estos organismos, se materializa el rol capitalista del Estado y la externalización de la política social. Los privados ahora reciben financiamiento "a través de la postulación a proyectos concursables" ". Esta lógica "genera y reproduce precarización y flexibilización laboral entre un gran segmento de los trabajadores vinculados a sus dependencias y programas" ${ }^{\text {, }}$, quienes se caracterizan por ser "profesionales formados en el área social como psicólogos, sociólogos, antropólogos, trabajadores sociales, educadores

\footnotetext{
${ }^{2}$ Pávez, Javiera; Carrasco, Claudia; Peña, Teresa; Bilbao, Ma. Ángeles; Oriol, Xavier; Ortúzar, Harry; Rubio, Andrés; Torres, Javier, "Sujeto/a trabajador/a en la política pública de intervención psicosocial de infancia en Chile: un análisis crítico del discurso", Revista de estudios cotidianos, 2016, 4(1): 23-45. Disponible en: https://dialnet.unirioja.es/servlet/articulo?codigo $=5568032$

${ }^{3}$ Bravo, Francisco; León, Beatriz, "Precariedad Laboral: el caso de los trabajadores del Área Social", Tesis para optar al grado de Licenciado/a en Trabajo Social, Tesis para optar al título de Asistente Social, Universidad Academia de Humanismo Cristiano, Santiago de Chile, 2016. Disponible en: http://bibliotecadigital.academia.cl/bitstream/handle/123456789/3839/TTRASO\%20487.pdf. De acuerdo a Bravo y León: "Estado (primer sector), mercado (segundo sector) y sociedad civil y/o iniciativas privadas sin fines de lucro (tercer sector)" (p. 58).

${ }^{4}$ Arredondo, Félix; Vidal, Paula, "Trabajadores del área social. El estado en cuestión", Ponencia presentada en el XXIX Congreso de la Asociación Latinoamericana de Sociología, Chile, 2013. Disponible en: http://actacientifica.servicioit.cl/biblioteca/gt/GT18/GT18_Arredondo_Vidal.pdf; Bravo y León, op. cit.

${ }^{5}$ Esta política en Chile se condensa principalmente en las responsabilidades del Ministerio de Desarrollo Social y de otros organismos como el Ministerio del Trabajo y Previsión Social, el Ministerio de la Mujer y la Equidad de Género, y el Servicio Nacional de Menores (SENAME) (Solidaridad, "Nace FENTTAS, herramienta de lucha de las y los trabajadores del área social", 2016. Disponible en http://www.periodicosolidaridad.cl/2016/07/21/nace-fenttas-herramienta-de-lucha-de-las-y-los-trabajadores-del-area-social/).

${ }^{6}$ Arredondo y Vidal, op. cit.; Pávez et al., op. cit., Bravo y León, op. cit.

${ }^{7}$ Bravo y León, op. cit.

${ }^{8}$ Para un examen del rol del Estado, coherente con el enfoque marxista de este escrito, véase: Meiksins Wood, E., Democracy against capitalism. Renewing historical materialism, Cambridge University Press, 1995; Meiksins Wood, E., Empire of capital, Verso, 2005; Shaikh, A. \& Tonak, E., "The Welfare State and the Myth of the Social Wagewith", en Cherry, R. et al., The imperiled economy, Book I, Union for Radical Political Economics, 1987; y Shaikh, A., "Who pays for the 'Welfare' in the Welfare State? A multicountry study", Social research, vol. 70, n. 2., 2003.

${ }^{9}$ Arredondo y Vidal, op. cit., 16.

${ }^{10}$ Ibídem, 14.
} 
populares, artistas, etc."11. Este sector "emplea a más de trescientas mil personas de forma remunerada y voluntaria, y su principal fuente de ingresos son fondos gubernamentales"12.

Dicha precarización, sostenida en la complicidad entre el Estado y las OSFL, no ha sido muy estudiada en nuestro país, y sólo recientemente a través de algunos aportes, como los de Arredondo y Vidal ${ }^{13}$, Pávez et al $^{14}$ y Bravo y León ${ }^{15}$ podemos ver que se expresa de diversas formas ${ }^{16}$. En primer lugar existe un déficit de recursos económicos, infraestructurales, materiales y humanos para hacer frente a la labor exigida ${ }^{17}$, lo cual se suma a los bajos salarios ${ }^{18}$ y la necesidad por parte de quienes trabajan de realizar ahorro forzoso $^{19}$. Junto con ello, en segundo lugar se advierten efectos subjetivos en quienes trabajan en estas entidades, tales como inseguridad ante posibles accidentes, despidos, enfermedades, u otros hechos similares, que implican una fuerte rotación y baja proyección en los lugares de trabajo ${ }^{20}$. Se suman a ello, lógicas de voluntarismo que apuntan a invisibilizar la precariedad laboral en pos de cumplir con la labor social, y de mecanización del trabajo ${ }^{21}$. Todo ello genera efectos en la salud de quienes trabajan, los cuales se expresan en la alta solicitud de licencias médicas por desgaste laboral (burnout) ${ }^{22}$. Finalmente, en términos políticos, todo lo anterior genera efectos de desesperanza y baja criticidad (Arredondo y Vidal, 2013) que minan las posibilidades de generar procesos de participación entre quienes trabajan y las poblaciones atendidas ${ }^{23}$. Todos estos elementos son coherentes con las transformaciones que la clase trabajadora chilena en general ha sufrido en las últimas décadas, fruto de un modo de producción capitalista en su faceta neoliberal ${ }^{24}$, el cual ha causado efectos tales como

${ }^{11}$ Ibídem, 1.

12 Bravo y León, op. cit., 64.

${ }^{13}$ Arredondo y Vidal, op. cit.

${ }^{14}$ Pávez et al, op. cit.

${ }^{15}$ Bravo y León, op. cit.

${ }^{16}$ En relación a ello, recurriremos en ocasiones a los datos de Fundación Sol. No obstante, los datos de esta entidad deben ser leídos críticamente, debido a que no necesariamente han sido elaborados desde un enfoque marxista. Además, esta organización es una fundación - figura que han asumido variadas OSFL- que obtiene financiamiento a través de proyectos, en los cuales no se descarta la participación del Estado (Fundación Sol, "Cómo nos financiamos". Disponible en http://www.fundacionsol.cl/fundacion/como-nosfinanciamos/). A pesar de ello, hemos escogido utilizar dichos datos ya que ofrecen un panorama estadístico que critica el entregado por el Estado, buscando dar cuenta "del conflicto de clases que el país engendra" (Fundación Sol, “Objetivos”. Disponible en: http://www.fundacionsol.cl/fundacion/quienessomos/). Daremos cuenta de dicho cuestionamiento, contrastando las cifras de Fundación Sol con las entregadas por el Instituto Nacional de Estadísticas, cada vez que sea posible. Esta misma advertencia sobre el carácter no marxista de las fuentes debe ser considerada para las referencias periodísticas utilizadas posteriormente.

${ }^{17}$ Pávez et al, op. cit.; Arredondo y Vidal, op. cit.

${ }^{18}$ Bravo y León, op. cit.

${ }^{19}$ Arredondo y Vidal, op. cit.

${ }^{20}$ Arredondo y Vidal, op. cit.; Pávez et al., op. cit., Bravo y León, op. cit.

${ }^{21}$ Arredondo y Vidal, op. cit.

22 Maslach, Christina y Susan Jackson, MBI: Maslach Burnout Inventory. Manual. Palo Alto, California, University of California, Consulting Psychologists Press, 1981.

${ }^{23}$ Pávez et al., op. cit.

${ }^{24}$ Para una comprensión crítica del neoliberalismo, coherente con el enfoque marxista de este escrito, véase: Shaikh, A., "The economic mythology of neoliberalism", en Saad-Filho, A. (ed.), Neo-Liberalism: a critical reader, Pluto Press, London; Shaikh, A., "Marxian competition versus perfect competition: further comments 
inestabilidad en el empleo y altas tasas de rotación, desempleo y precarización del mismo, desprotección legislativa de los trabajadores, segmentación y exclusión en la seguridad social, pérdida de derechos adquiridos y disminución de exigencias reivindicativas, debilitamiento del rol del estado, y fortalecimiento de la autonomía empresarial que define unilateralmente las condiciones de trabajo, de salarios y los márgenes de rentabilidad que quiere alcanzar ${ }^{25}$.

El análisis que ofrecemos a continuación pretende mostrar cómo esta forma de hacer política pública y los efectos nocivos de aquella en quienes componen la fuerza de trabajo del área social en Chile, se explican y sostienen, entre otras cosas, a través de las relaciones sociales de producción entre Estado, privados y clase trabajadora, de acuerdo a las lógicas de un sistema económico capitalista. Ello nos lleva a sostener que el fenómeno de la precariedad laboral en general, es algo que va más allá del modelo neoliberal ${ }^{26}$, encontrando sus raíces en el modo de producción capitalista, desde sus albores. Karl Marx, examinó en detalle dichas formas de precariedad en la Inglaterra del siglo XIX ${ }^{27}$, caracterizaciones que, en muchos sentidos, siguen estando completamente vigentes para las condiciones de trabajo actuales en Chile y en el mundo entero ${ }^{28}$. Es por ello, que las formas de precariedad que vive el área social actualmente pueden ser explicadas atendiendo a lo que Marx entiende por la categoría de explotación. Bajo este supuesto y con el fin de realizar dicho análisis, recurriremos a los aportes de Karl Marx presentes en su obra cúlmine, El capital, crítica de la economía política.

Si bien la categoría de explotación propuesta por Marx ha protagonizado variados debates posteriores ${ }^{29}$, nuestro afán aquí no será problematizar dicha categoría marxiana,

on the so-called choice of technique", The cambridge journal of economics, 1980, n. 4, 75-83; Kliman, A. The failure of capitalist production. Underlying causes of great recession, Pluto Press, 2011.

${ }^{25}$ Pascual, M., "Chile: ¿más cerca o más lejos del trabajo decente?", Le Monde Diplomatique "El trabajo" (pp. 7-18), Santiago, Editorial Aún creemos en los sueños, 2007, p. 9.

${ }^{26} \mathrm{La}$ precariedad laboral no sólo es un fenómeno que emerge en contextos de política neoliberal. Por ejemplo, los llamados 'minijobs' en Alemania, en conjunto con la aplicación de las reformas Hartz IV (Arbeitslosengeld II), son un ejemplo de precarización laboral en complicidad con la socialdemocracia alemana. Véase La nación, "La precariedad laboral, el lado oscuro de la exitosa política económica de Merkel". Disponible en: http://www.lanacion.com.ar/2065675-la-precariedad-laboral-el-lado-oscuro-de-laexitosa-politica-economica-de-merkel.

${ }^{27}$ Véase Marx, Karl, El capital, crítica de la economía política, Libro primero, El proceso de producción de capital, vol. I, Siglo XXI, México, 2008, 1a edición. El capítulo VIII, "La jornada laboral”, ofrece múltiples ejemplos de precariedad laboral en distintas ramas de la industria.

${ }^{28}$ Dicha precariedad no es exclusiva para los países del 'tercer mundo', sino también se desarrolla en las grandes metrópolis, como es el caso de la 'gig-economy'. Esta se define como aquella modalidad de trabajo en la que un trabajador se transforma en proveedor de un servicio que es puesto a disposición del público consumidor a través una aplicación móvil (app) creada por una empresa, como es el caso de Uber. Véase ER, "The Gig Economy: Capitalism's New Normal", Disponible en: http://www.leftcom.org/en/articles/2016-1021/the-gig-economy-capitalism's-new-normal.

${ }^{29}$ Véase Holmstrom, Nancy, "Exploitation", Canadian journal of philosophy, 1977, Volume VII, Number 2, june; Bhaduri, Amit \& Robinson, Joan , "Accumulation and exploitation: an analysis in the tradition of Marx, Srafia and Kalecki", Cambridge Journal of Economies, 1980, 4, 103-115; Roemer, John E., A general theory of exploitation and class, Harvard University Press, 1982; Roemer, John E., "Exploitation, Alternatives and 
sino más bien ilustrar cómo el contexto de precariedad laboral del trabajo en el área social en Chile puede ser explicado a través de aquel concepto en su significación marxista original. Esto permite cumplir un objetivo secundario, el cual consiste en mostrar cómo la teoría de Marx, sin perjuicio de sus reformulaciones posteriores, sigue siendo útil para comprender y analizar la explotación laboral actual en Chile, al menos en el área social.

\section{La explotación capitalista del trabajo en el área social en Chile}

Una de las formas más comunes de vínculo laboral en el área social en Chile es el llamado «contrato a honorarios». Según Bravo y León, el “60,64\% de los profesionales que trabajan en el área de servicios sociales y de salud, lo hacen bajo la modalidad de honorarios y el 69,18\% de los profesionales que trabajan en educación también, están sujetos a la misma modalidad de inserción laboral" 30 . Quienes trabajan bajo esta figura no se rigen por el Código del Trabajo, más bien se acogen al Código Civil, "razón por la cual los Servicios del Trabajo no tienen competencia para conocer y pronunciarse sobre los conflictos derivados de tal contrato" ${ }^{31}$. Esto se vincula con aquellas cifras que muestran que en Chile "el 39,7 \% del total del empleo no está protegido bajo ninguna norma laboral"32. De este modo, el mal llamado contrato a honorarios se transforma en una idónea forma de dominación que permite al capitalismo explotar a sus trabajadorxs al amparo de la legalidad de un Estado cómplice. Y si bien, una parte de quienes trabajan en esta área también poseen formas de contrato más estables, ello no asegura la garantía plena de sus derechos laborales.

En este escenario, el capitalismo da rienda suelta a lo que Marx denominó «explotación», categoría que debe ser comprendida junto con la de «plusvalor». Según Marx, "la tasa de plusvalor (...) es la expresión exacta del grado de explotación de la fuerza de trabajo por el capital, o del obrero por el capitalista"33. ¿Qué significa esto? Que la explotación en el área social debemos entenderla como una relación entre dos clases, la clase capitalista y la clase trabajadora, en donde la primera, compuesta, a grandes rasgos, por el Estado y las OSFL, obliga a la segunda a crear "no sólo valor, sino plusvalor" 34 . ¿Qué es el plusvalor? Marx plantea que la clase capitalista, mediante la compra de la fuerza

Socialism", The Economic Journal, 1982, 92(365), 87-107; Roemer, John E., "New directions in the Marxian Theory of exploitation and class", Politics \& Society, 1982, September 1, Volume: 11 issue: 3, page(s): 253287; Wolff, Johnatan, "Marx and explotaition", The Journal of Ethics 3, 1999, 105-120; Wright, Erik Olin, "Exploitation, identity, and class structure: a reply to my critics", Critical Sociology, 1988, 15. 1, pp. 91-110; Brewer, J. "Exploitation in the new Marxism of collective action". The Sociological Review, 1987, 35: 84-96.

${ }^{30}$ Bravo y León, op. cit., 66.

31 Gobierno de Chile, Dirección del Trabajo, “¿Cuáles son los derechos de las personas contratadas a honorarios?", 2017. Disponible en http://www.dt.gob.cl/consultas/1613/w3-article-60764.html

${ }^{32}$ Fundación Sol, "Informe Mensual de Calidad del Empleo (IMCE). Análisis de los microdatos liberados el 30 de Septiembre de 2015, correspondiente al trimestre móvil Junio - Agosto 2015”, septiembre de 2015, p. 13. Esta cifra contrasta por la entregada por el Instituto Nacional de Estadísticas, la cual es equivalente a un 10,89\% (874.444 trabajadorxs de un total de 8.028.202) para el trimestre móvil julio-septiembre del mismo año (Instituto Nacional de Estadísticas, Banco de datos de la Encuesta Nacional de Empleo. Disponible en: http://bancodatosene.ine.cl).

${ }^{33}$ Marx, Karl, El capital, crítica de la economía política, Libro primero, El proceso de producción de capital, vol. I, Siglo XXI, México, 2008, 1a edición, p. 262.

${ }^{34}$ Ibíd., 226. 
de trabajo y la producción de mercancías ${ }^{35}$, busca siempre un incremento o excedente por encima del valor originario utilizado; a dicho incremento Marx lo denomina plusvalor ${ }^{36}$. Este plusvalor, creado por la fuerza de trabajo en el área social, es sustraído por el Estado y las OSFL para acrecentar el capital que ya poseen: "el misterio de la autovalorización del capital se resuelve en el hecho de que éste puede disponer de una cantidad determinada de trabajo ajeno impago" "37. De este modo, la explotación es un proceso que implica, para la clase trabajadora, la creación de un plusvalor que resulta enajenado, y por tanto la recepción de un salario cercenado.

La explotación, en el contexto del contrato a honorarios, no posee impedimento legal alguno que la detenga, no obstante veremos que en otras formas de contratación también es posible tal azote. Recurriremos a dos categorías planteadas por Marx en El capital para comprender la explotación en el trabajo en el área social en Chile; estos son el «salario por tiempo» y el «salario a destajo», expresiones del salario que Marx definió como "las dos formas básicas predominantes" en el capitalismo ${ }^{38}$. Vincularemos las características del trabajo del área social con estas dos formas de obtención del salario y, respectivamente, con dos formas de creación de plusvalor, estas son el «plusvalor absoluto» y el «plusvalor relativo» ${ }^{39}$. De este modo veremos cómo el Estado y las OSFL participan en los procesos de acumulación de capital y por tanto logran posicionarse como clases dominantes.

\subsection{La explotación y el plusvalor absoluto: la jornada parcial y la inestabilidad laboral como formas de salario por tiempo}

Uno de los elementos clave de la precariedad laboral en esta área se relaciona con el carácter limitado del tiempo de trabajo ${ }^{40}$. Este carácter se expresa en dos formas.

En términos 'microscópicos', este carácter limitado del tiempo se expresa como «jornada parcial», es decir como jornada con una cantidad de horas inferior a la jornada completa. Ésta ha sido definida, para el caso chileno, como una jornada "no superior a dos

\footnotetext{
${ }^{35}$ Ibíd., 225-226.

${ }^{36}$ Ibíd., 184.

${ }^{37}$ Ibíd., 649.

${ }^{38}$ Marx, Karl, El capital, crítica de la economía política, Libro primero, El proceso de producción de capital, vol. II, Siglo XXI, México, 2009, 1a edición, p. 661.

39 Para motivos de nuestro análisis comprenderemos la relación entre plusvalor absoluto y relativo de un modo dialéctico, tal como lo formula Marx en El capital: "Desde cierto punto de vista, la diferencia entre el plusvalor absoluto y el relativo parece ser enteramente ilusoria. El plusvalor relativo es absoluto, pues trae aparejada una prolongación absoluta de la jornada laboral, por encima del tiempo de trabajo necesario para la existencia del obrero mismo. El plusvalor absoluto es relativo, pues condiciona un desarrollo de la productividad laboral que permite confinar el tiempo de trabajo necesario a una parte de la jornada laboral. Pero si tenemos en cuenta el movimiento del plusvalor, esa apariencia de identidad se desvanece" (Marx, 2009, p. 619). Por otro lado, si bien las categorías de plusvalor absoluto y relativo son correlativas a las de salario por tiempo y salario a destajo, respectivamente, no debe suponerse que éstas siempre coinciden o se presentan de manera dual y lineal; por ello, debe advertirse la necesidad de diferenciar entre explotación y remuneración.

${ }^{40}$ Arredondo y Vidal, op. cit., 5.
} 
tercios de la jornada ordinaria" ${ }^{41}$, es decir, igual o menor a 30 horas semanales. En Chile, el porcentaje de personas que trabajan una jornada parcial es de un $52,1 \%{ }^{42}$, jornada que también ha sido denominada como «trabajo part-time» ${ }^{43} \mathrm{o}$ «temporario» ${ }^{44}$.

En términos 'macroscópicos', este carácter limitado del tiempo se expresa como «inestabilidad laboral» ${ }^{45}$, lo cual, desde un punto de vista temporal, dice relación con la interrupción constante del vínculo laboral por parte del empleador, que implica períodos irregulares y consecutivos de trabajo y cesantía ${ }^{46}$. Esto se da no sólo en el caso del contrato a honorarios, sino además en figuras legales como el «contrato a plazo fijo» y el «contrato por faena», siendo estos tres tipos de contrato los que poseen la mayoría de quienes trabajan en esta área, siendo el «contrato indefinido» una excepción a la norma ${ }^{47}$. Tanto el contrato a plazo fijo y por faena se definen por su carácter de temporalidad limitada, estableciendo la finalización del vínculo laboral a través de una fecha o de la culminación de una faena específica, respectivamente ${ }^{48}$. Si bien en términos legales, ambas figuras no pueden ser renovadas - el contrato a plazo fijo no puede durar más de un año y el contrato por faena no se puede renovar por la misma tarea ${ }^{49}$ - las OSFL no respetan dicha norma, ya que de lo contrario deberían establecer un contrato indefinido, lo cual supone obstáculos legales a la explotación. Ante todo esto, se suma el sistema de licitaciones, el cual otorga a los programas implementados una duración de uno a tres años, lo cual también sirve de argumento para el término de los vínculos contractuales ${ }^{50}$. La temporalidad limitada en este caso no es a nivel semanal, como en la jornada parcial, sino a nivel mensual o anual, existiendo meses o años en los que se puede o no estar trabajando.

Ambas expresiones de la temporalidad limitada, tanto la jornada parcial como la inestabilidad laboral, no son excluyentes, encontrándonos con personas que teniendo un contrato a honorarios, a plazo fijo o por faena, trabajan a jornada parcial; así también es posible la jornada parcial en quienes están con contrato indefinido ${ }^{51}$.

Desde Marx, esta temporalidad limitada se explica desde la categoría de «salario por tiempo», el cual se define como "la venta de fuerza de trabajo (...) por espacios de tiempo determinados" 52 , lo cual coincide con la primera forma de fijar las remuneraciones en Chile: "por unidad de tiempo, día, semana, quincena o mes"53. Este salario se puede

41 Gobierno de Chile, Dirección del Trabajo, Código del Trabajo, julio de 2017, p. 42. Disponible en: http://www.dt.gob.cl/legislacion/1611/articles-95516_recurso_2.pdf

${ }^{42}$ Fundación Sol, "Informe Mensual...", op. cit., 7. Esta cifra contrasta con la entregada por el Ministerio del Trabajo, para el trimestre móvil abril mayo junio del mismo año, equivalente al 46,6\% (Instituto Nacional de Estadísticas, Empleo Trimestral, edición n. 201, 31 de julio de 2015, p. 8).

43 Pávez et al., op. cit., 29.

${ }^{44}$ Antúnes en Arredondo y Vidal, op. cit., 2.

45 Arredondo y Vidal, op. cit., 9; Pávez et al., op. cit., 28; Bravo y León, op. cit., 35.

${ }^{46}$ Arredondo y Vidal, op. cit., 11.

${ }^{47}$ Arredondo y Vidal, op. cit., 6; Pávez et al., op. cit., 29; Bravo y León, op. cit., 86.

${ }^{48}$ Gobierno de Chile, Código del trabajo..., op. cit., 89.

49 Gobierno de Chile, Dirección del Trabajo, “¿Puede renovarse un contrato por obra o faena?”, 2017. Disponible en http://www.dt.gob.cl/consultas/1613/w3-article-67706.html

${ }^{50}$ Pávez et al., op. cit., 26.

${ }^{51}$ Gobierno de Chile, Código del trabajo..., op. cit., 42.

${ }^{52}$ Marx, 2009, op. cit., 661.

${ }^{53}$ Gobierno de Chile, Código del trabajo..., op. cit., 44. 
calcular en base al valor medio de la hora de trabajo multiplicado por el número de horas trabajadas ${ }^{54}$.

Calculemos dicho salario por tiempo, siguiendo la fórmula de Marx, considerando la realidad chilena. El valor del sueldo mínimo en Chile, de $\$ 270.000$, sirve de referencia del valor medio de la jornada laboral, considerando además que "el 53,5\% de los trabajadores chilenos gana menos de $\$ 300.000 " 55$. Si estos $\$ 270.000$ se dividen por 45 horas, es decir, el número de horas semanales de una jornada laboral completa ${ }^{56}$, esto arroja un 'valor hora' de $\$ 6.000$. Teniendo en cuenta este valor hora, ahora es posible calcular el valor real del salario por tiempo de una persona sujeta a jornada parcial e inestabilidad laboral. Imaginemos a una persona que posee una jornada parcial de 16 horas semanales y debido a su situación de inestabilidad laboral sólo ha trabajado 10 meses del total de 12 que posee el año. Para determinar el valor del salario de la jornada parcial multiplicamos el valor hora de $\$ 6.000$ por las 16 horas, lo cual arroja un salario mensual de $\$ 96.000$. Para determinar el valor del salario, considerando la inestabilidad laboral, multiplicamos dicho salario de $\$ 96.000$ por la cantidad de meses trabajados en el año, es decir 10, y dividimos luego por 12 meses, lo cual nos arroja un salario mensual de $\$ 80.000$. De este modo vemos cómo quienes trabajan a cambio de un salario por tiempo obtienen un ingreso muy menor al sueldo mínimo.

¿Por qué es importante este cálculo del salario por tiempo? Para Marx, la jornada laboral está constituida por dos componentes fundamentales: el «trabajo necesario» y el «plustrabajo». Mientras el trabajo necesario es aquella parte de la jornada laboral requerida para la subsistencia y reproducción de la clase trabajadora, la cual se expresa concretamente en el salario destinado a la compra de medios de subsistencia (alimentación, abrigo, techo, etc.); el plustrabajo es aquella parte de la jornada destinada a la producción de plusvalor, siendo éste último expropiado por la clase dominante para la autovalorización del capital, siendo entonces un trabajo impago ${ }^{57}$. Marx, al definir la categoría de trabajo necesario, definió la duración mínima de la jornada laboral. Es decir, la jornada laboral no puede ser menor al tiempo de trabajo necesario, ya que se trata de "un límite mínimo, la parte de la jornada que el obrero tiene necesariamente que trabajar para la subsistencia de sí mismo"58 (véase figura 1).

\footnotetext{
${ }^{54}$ Marx, 2009, op. cit., 662.

55 Fundación Sol, "Los verdaderos sueldos de Chile: panorama actual del valor del trabajo usando la Encuesta NESI”, 2015, p. 3. Disponible en: http://www.fundacionsol.cl/wp-content/uploads/2015/06/VerdaderosSalarios-2015.pdf. Esta cifra discrepa con la entregada por el Instituto Nacional de Estadísticas para el año 2013; a pesar de ello sigue siendo relevante esta última, la cual plantea que el $40 \%$ de los hogares chilenos no posee un ingreso superior a $\$ 351.613$, y que el $80 \%$ del ingreso per cápita no supera los $\$ 292.152$ (Instituto Nacional de Estadísticas, VII Encuesta de presupuestos familiares. Resultados VII EPF, septiembre de 2013, p. 20. Disponible en: http://www.ine.cl/estadisticas/ingresos-y-gastos/vii-epf-resultados)

56 Gobierno de Chile, Código del trabajo..., op. cit., 29.

${ }^{57}$ Marx, 2008, op. cit., 261.

${ }^{58}$ Ibíd., 278.
} 
Figura 1.

Trabajo necesario y plustrabajo

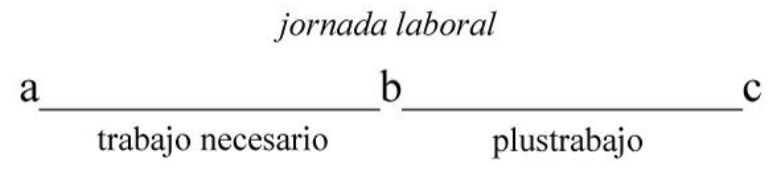

No obstante, el salario por tiempo lo que hace es transgredir ese límite mínimo; en palabras de Marx:

Si el salario por hora se fija de tal manera que el capitalista no se obliga a pagar un jornal, o un salario semanal, sino únicamente las horas de trabajo en las cuales tiene a bien ocupar al obrero, podrá ocuparlo durante menos tiempo del que originariamente sirvió de base para estimar el salario por hora (...) El capitalista puede ahora arrancar al obrero determinada cantidad de plustrabajo sin concederle el tiempo de trabajo necesario para su autoconservación ${ }^{59}$.

De este modo el carácter limitado del trabajo provoca una disminución de los salarios por debajo del valor mínimo correspondiente al trabajo necesario, lo cual no impide la extracción del plusvalor respectivo por parte del capitalista. Según el estudio de Bravo y León (2016), "el 43,6\% de los encuestados gana menos de 500.000 mil pesos brutos",60, a esto se agrega que "la tendencia mayor de los entrevistados está en el rango de los \$400 y $\$ 450$ mil por jornada completa (...) casi la totalidad de los entrevistados —a excepción de un solo dirigente- perciben ingresos que no superan los $\$ 650$ mil pesos" ${ }^{\prime \prime}$. Sin embargo, si consideramos que probablemente la mayoría de estos entrevistados, y la mayor parte de quienes trabajan en el área social, poseen una jornada parcial y contratos que implican inestabilidad laboral, entonces estas cifras pueden descender drásticamente dependiendo de cada situación, según el cálculo hecho anteriormente. No sólo estamos ante bajos salarios, sino ante salarios miserables que ni siquiera permiten sobrevivir.

La obtención de un salario menor al mínimo necesario obliga a quienes trabajan en el área social a buscar otras fuentes de subsistencia. Bravo y León ${ }^{62}$ evidencian que al menos el $50 \%$ de las personas vinculadas a su estudio "mantienen otro vínculo laboral (...) los que trabajan media jornada mantiene otra relación laboral y así completar 'un sueldo', otros que mantienen contrato por jornada completa en un lugar, continúan con otra relación contractual anexa" 63 , quienes relatan esto, agregan que "en un sólo trabajo no les alcanza para vivir"64. Marx lo explica claramente al sostener que

\footnotetext{
${ }^{59}$ Marx, 2009, op. cit., 664-665.

${ }^{60}$ Ibid., 4.

${ }^{61}$ Ibíd., 75.

${ }^{62}$ Bravo y León, op. cit.

63 Ibíd., 74.

64 Ídem.
} 
cuanto menor sea el precio del trabajo, tanto mayor tendrá que ser la cantidad de trabajo o tanto más extensa la jornada laboral para que el obrero se asegure apenas un miserable salario medio (...) la prolongación de la jornada laboral produce a su vez una baja en el precio del trabajo ${ }^{65}$.

De esta forma se demuestra que, tras la figura legal de la jornada parcial o de los contratos a honorarios, a plazo fijo o por faena, existe en la práctica una jornada laboral que podríamos llamar completa, y que no es reconocida legalmente como tal, aunque se distribuya entre diferentes empleadores. Por otro lado, es tal el grado de precariedad salarial que incluso quienes trabajan legalmente a jornada completa buscan otros empleos, lo cual demuestra que este tipo de jornada no es más que parcial en la realidad. Las paupérrimas condiciones de trabajo en el área social nos muestran el reverso negativo o dialéctico de la jornada, dimensión que el Estado esconde tras nomenclaturas legales. Del carácter limitado del tiempo de trabajo hemos transitado a la prolongación indefinida de la jornada laboral. Esto es coherente con lo que Marx afirma respecto a la explotación: “apropiarse de trabajo durante todas las 24 horas del día es, por consiguiente, la tendencia inmanente de la producción capitalista" (Marx, 2008, p. 309).

Esta prolongación de la jornada también se expresa de forma camuflada a través de las llamadas «horas extras», las cuales se calculan a partir del ingreso mínimo mensual, considerando "proporcionalmente a la cantidad de horas pactadas como jornada"66. Ya sabemos que de nada sirve la referencia al sueldo mínimo si el cálculo es proporcional a las horas, en un contexto de temporalidad limitada. Tampoco las horas extras podrán, de este modo, alcanzar el mínimo de subsistencia ligado al trabajo necesario. Marx afirma que, en esta modalidad "se paga mejor, aunque a menudo en proporción ridículamente exigua (...) el bajo precio del trabajo durante el llamado horario normal obliga al obrero, si quiere obtener un salario suficiente, a efectuar horas extras, mejor remuneradas" 67 . La realidad en Chile de quienes trabajan en el área social es incluso peor; como evidencian Bravo y León, "al 78\% de los encuestados no le cancelan las horas extras o sobre tiempo"68.

Ante todo esto, el capitalista observa un escenario en donde, por un lado, quienes trabajan en el área compiten por obtener un trabajo extra que les permita subsistir, y por otro, algunas personas son capaces de trabajar en más de un lugar, y por ello, pueden producir más que otros. Esta trágica visión se torna alegre para las OSFL ya que

si un hombre ejecuta el trabajo de $1 \frac{1}{2}$ o de 2 hombres, el aflujo de trabajo aumenta aunque la oferta de las fuerzas de trabajo que se hallan en el mercado permanezca constante. La competencia que se genera de esta suerte entre los obreros, pone al capitalista en condiciones de reducir el precio del trabajo, y a la baja de este precio le permite, a su vez, prolongar aún más el horario de trabajo ${ }^{69}$.

\footnotetext{
${ }^{65}$ Marx, 2009, op. cit., 667-668.

${ }^{66}$ Gobierno de Chile, Código del trabajo..., op. cit., 42.

${ }^{67}$ Marx, 2009, op. cit., 666.

${ }^{68}$ Bravo y León, op. cit., 4.

${ }^{69}$ Marx, 2009, op. cit., 668.
} 
Así, se fraguan las condiciones que permiten no sólo la precariedad económica, sino la instalación de valores neoliberales como la competencia en la misma clase trabajadora. Esto asegura no sólo la opresión material de quienes trabajan en el área sino una alienación subjetiva que impide cuestionar al modelo político subyacente.

Hasta aquí hemos visto cómo la temporalidad limitada se expresa en el área social como jornada parcial y como inestabilidad laboral, ambas basadas en formas precarias de contratación no indefinida que implican la no obtención de un salario equivalente al trabajo necesario para la reproducción de la clase trabajadora. Esto fuerza a quienes integran este sector a buscar otros empleos y a trabajar horas extras, lo cual implica la prolongación de la jornada laboral. Esta prolongación de la jornada si bien busca la subsistencia de quienes trabajan, necesariamente implica a la vez la prolongación del plustrabajo. De esta forma lo que parecía parcial y definido en términos legales, es más bien completo en la realidad, y lo que parecía completo en términos de jornada llega incluso a ser parcial. Estamos frente a la primera forma de explotación en el área social ligada a la producción y usurpación del plusvalor absoluto (véase figura 2):

la producción de plusvalor absoluto consiste simplemente, por un lado, en la prolongación de la jornada laboral más allá de lo límites de los tiempos de trabajo necesario para la subsistencia del propio obrero, por otro en la apropiación del plustrabajo por el capital"70.

Figura 2.

Plusvalor absoluto

jornada laboral A

a trabajo necesario $\mathrm{A}_{\text {plustrabajo } \mathrm{A}} \mathrm{b}$

jornada laboral $B$

$\begin{aligned} \text { a } & \text { plustrabajo B } \\ \text { trabajo necesario } \mathrm{B} & \mathrm{b}_{\text {jornada laboral } A}<\text { jornada laboral } B \\ \text { trabajo necesario } A & =\text { trabajo necesario } B \\ \text { plustrabajo } A & <\text { plustrabajo } B\end{aligned}$

\subsection{La explotación y el plusvalor relativo: el trabajo por metas y los incentivos de la burocracia como formas de trabajo a destajo}

Otra de las características clave en esta área es el permanente control del desempeño laboral de quienes trabajan, desempeño asociado al logro de ciertos productos, objetivos o

${ }^{70}$ Marx, 2009, op. cit., 617. 
metas cuantificables o medibles ${ }^{71}$, lo cual posee un efecto de tecnificación del quehacer que puede transformar a quienes trabajan en meros operadores ${ }^{72}$. Este control, por un lado, supone que a mayor cantidad de productos o metas logradas existe una mayor resolución de los problemas sociales con los cuales cada organización trabaja; sin embargo, no considera que existen brechas entre lo cuantitativo y lo cualitativo, o entre el abordaje de los problemas sociales y el abordaje de sus causas propiamente tales. No obstante, por otro lado, este control expresa una específica organización social del trabajo, ya que es un control unilateral, jerárquico, descendente; baja desde el Estado a los privados y de los privados a la clase trabajadora. Es este último aspecto el que nos interesa.

El control del trabajo mediante productos o evidencias en el área social emerge a finales de los años 90, al alero de un proceso de 'modernización' del Estado posdictatorial, denominado Programa de Mejoramiento de Gestión $(\mathrm{PMG})^{73}$. Este programa implicó la consolidación del nuevo management público, fenómeno que importó las lógicas de gestión empresarial al Estado y sus diversos organismos asociados ${ }^{74}$. En este contexto se crean dos leyes que asocian el control del desempeño y el cumplimiento de objetivos a la entrega de incentivos económicos para quienes trabajan en el Estado; mientras la ley 19.553 creada en 1998 regula el desempeño colectivo; la ley 19.882, creada en 2003, regula el desempeño de altos directivos y profesionales del sector público ${ }^{75}$. La obtención de estos incentivos variables puede significar hasta un $30 \%$ de la remuneración total ${ }^{76}$. Esta política implicó "medir de manera precisa el rendimiento efectivo de cada individuo, equipo de trabajo o unidad" "77.

Marx ya había evidenciado los beneficios psicológicos que la entrega de estos incentivos implicaban para el capitalista, señalando los relatos de los mismos obreros: "pensamos continuamente en la recompensa de salir más temprano por la noche, y un espíritu activo y alegre impregna toda la fábrica, desde el ayudante más joven hasta el operario más antiguo y además podemos ayudarnos mucho unos a otros"78. Sin embargo, debido a la externalización de la política social, esta medición del desempeño del Estado no implica un autocontrol de su propia labor, sino más bien el control hacia quienes trabajan directamente en los programas, el control hacia la clase trabajadora del área social. Como dichos incentivos "sólo se entregan a los funcionarios"79 y no a quienes trabajan en situación de subcontratación, la clase trabajadora es controlada con el fin de acrecentar los salarios de quienes trabajan en el Estado. De esta forma la política de incentivos al

\footnotetext{
${ }^{71}$ Arredondo y Vidal, op. cit.; Cornejo, Miguel, "Gestión Pública, Incentivos y Remuneraciones en Chile", Revista de estudios politécnicos, 2009, vol VII, n. 11: 1-15. Disponible en: http://www.scielo.mec.pt/pdf/tek/n11/n11a05.pdf

${ }^{72}$ Pávez et al., op. cit.

73 Tello, Felipe, "La política de reforma y modernización de la gestión pública en Chile. Actores y procesos", Universium, 2011, 26(2): 245-265, https://doi.org/10.4067/S0718-23762011000200012; Cornejo, op. cit.

74 Tello, op. cit., 252.

75 Madrid, Patricio, "Un análisis a la efectividad del uso de incentivos al desempeño en el sector público", Seminario para optar al Título de Ingeniería Comercial, Mención Economía, Universidad de Chile, Santiago de Chile, 2013, p. 25. Disponible en: http://repositorio.uchile.cl/handle/2250/112133

${ }^{76}$ Cornejo, op. cit., 7.

${ }^{77}$ Ibíd., 2.

${ }^{78}$ Marx, 2009, op. cit., 502.

${ }^{79}$ Madrid, op. cit., 25.
} 
desempeño se fracciona en dos partes, mientras el control del desempeño basada en productos hostiga a la clase trabajadora del área social, los incentivos económicos asociados a dicho desempeño engrosan los bolsillos de la burocracia estatal ${ }^{80}$.

Lo anterior se expresó en 2015 en las inverosímiles cifras de porcentaje de logro de objetivos por parte de diversas entidades estatales como el Registro Civil (95,8\%), el Servicio Nacional de Menores (92\%) y la Dirección de Presupuestos (100\%), lo cual implicó "un pago de $\$ 82$ mil millones a funcionarios estatales" $"$. No es necesario argumentar lo insostenible de dichos porcentajes; basta considerar la crisis actual del SENAME, organismo que muestra "deficiencias graves en el sistema de protección de la infancia, tanto en el diseño como en la ejecución de planes y programas destinados a la infancia vulnerada" 82 . Un dirigente sindical de estas entidades privadas afirma que se "obligó por tres meses a trabajadores a subir a la plataforma de internet información falsa, atenciones que no se hacían figuraban como realizadas, lo que significó que cien niños no tuvieran atención" $" 83$.

Pues bien, el falseamiento de los porcentajes de logro implica que el Estado es consciente del fracaso de la política, certeza basada en el control efectivo del desempeño de quienes trabajan en el área social a través de diversos dispositivos. Si bien dicho control basado en el cumplimiento de metas no se expresa en incentivos para la clase trabajadora, sí condiciona la obtención del salario y muchas veces la continuidad del vínculo contractual. En este escenario se hace presente lo que Marx denomina el «salario a destajo»:

No se trata de medir el valor de la pieza por el tiempo de trabajo encarnado en ella, sino, a la inversa, de que el trabajo que ha gastado el obrero se mida por el número de piezas que ha producido. En el salario por tiempo el trabajo se mide por su duración directa; en el pago a destajo, por la cantidad de productos en que se condensa el trabajo durante un tiempo determinado. ${ }^{84}$

A diferencia del salario por tiempo, en el salario a destajo no se paga un salario por las horas trabajadas, sino por la cantidad de productos logrados independientemente del tiempo invertido en éstos. Esta es la segunda forma según la cual el Código del Trabajo fija las remuneraciones: "por pieza, medida u obra" 85 . No obstante, ambas lógicas no operan de

\footnotetext{
${ }^{80}$ Esto nos lleva a concebir los trabajadores del Estado como un sector que no genera plusvalor, más bien, como un sector que recibe un salario a través de la redistribución del plusvalor creado por la clase trabajadora del área social. En este sentido dicho sector estatal es una clase improductiva de trabajadores que, para obtener un salario, incide indirectamente en los modos de explotación sostenidos por las OSFL.

8124 horas, "Sename, Registro Civil y Gendarmería aparecen con índices de excelencia", 2016. Disponible en http://www.24horas.cl/nacional/sename-registro-civil-y-gendarmeria-aparecen-con-indices-de-excelencia2184075

${ }^{82}$ Gobierno de Chile, "Informe Comisión Especial Investigadora de la forma en que las autoridades han atendido las propuestas de la Cámara de Diputados, por la aprobación del Informe de la Comisión Investigadora del SENAME en el año 2014, y la situación de menores de edad carentes de cuidado parental", 2016, p. 449.

${ }^{83}$ Rebelión, "Campaña de trabajadores del área social: fin al lucro en políticas públicas”, 2015. Disponible en http://www.rebelion.org/noticia.php?id=204317

${ }^{84}$ Marx, 2009, op. cit., 673.

${ }^{85}$ Gobierno de Chile, Código del trabajo..., op. cit., 44.
} 
modo excluyente en la realidad chilena, más bien se conjugan de tal modo que a la prolongación de la jornada laboral ahora se suma un cumplimiento de metas determinado.

Ahora bien, el salario a destajo aparece para el capitalista como un modo de enfrentar las dificultades que puede ofrecer el salario por tiempo para la extracción de plusvalor. Ya que, si bien, la jornada parcial y completa, y diversas formas de contratación no indefinida, permiten, como vimos, una prolongación indefinida de la jornada laboral; el contrato indefinido podría ser - aparentemente - una posible piedra de tope a esta práctica, en la medida que provee una estabilidad laboral que posibilita hacer valer, entre otros derechos, la regulación de la jornada. En efecto, Marx destaca la regulación de la jornada laboral como una de las luchas más relevantes del proletariado para hacer frente a la producción de plusvalor absoluto ${ }^{86}$, lucha de la cual el proletariado chileno no estuvo exento en la conquista de las 8 horas. No obstante, ante esta conquista, la clase burguesa impone el salario a destajo, ya que éste no implica controlar la extensión de la jornada, sino más bien aumentar la productividad de aquella, brindando "al capitalista una medida rigurosamente precisa de la intensidad del trabajo" "87. Esto es coherente con el Código del Trabajo, el cual afirma, con respecto al control funcional de la jornada, "que no existe tal funcionalidad cuando el trabajador sólo entrega resultados de sus gestiones" 88 . De este modo, toda vez que quienes trabajan en el área social se resisten a prolongar su jornada, deben intensificarla para cumplir con las metas estipuladas por los programas, metas ante las cuales se subordina el salario. De este modo, quienes trabajan en el área social aumentan la proporción de plustrabajo con respecto a la de trabajo necesario en una misma jornada laboral.

Estamos frente a la segunda forma de explotación en el área social, mediante la producción de plusvalor relativo. En palabras de Marx: "La producción de plusvalor relativo presupone la producción de plusvalor absoluto (...) $\mathrm{Su}$ finalidad es el acrecentamiento del plusvalor por medio de la reducción del tiempo de trabajo necesario, independientemente de los límites de la jornada laboral" 89 . Dicho de otro modo, mientras el plusvalor absoluto extiende el plustrabajo al aumentar la jornada laboral, el plusvalor relativo extiende el plustrabajo sin modificar la extensión de la jornada laboral, sino más bien intensificando, esto es, disminuyendo la proporción de trabajo necesario (véase figura $3)$.

\footnotetext{
${ }^{86}$ Marx, 2008, op. cit.

${ }^{87}$ Marx, 2009, op. cit., 674.

${ }^{88}$ Gobierno de Chile, Código del trabajo..., op. cit., 43-44.

${ }^{89}$ Marx, 2009, op. cit., 617.
} 
Figura 3.

Plusvalor relativo

jornada laboral $A$

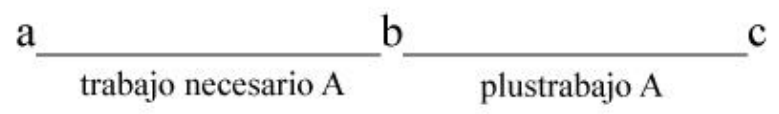

jornada laboral C

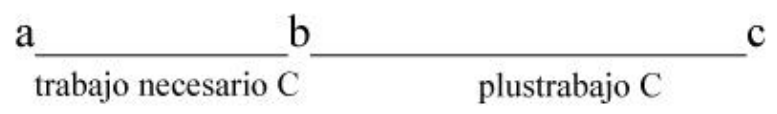

jornada laboral $A=$ jornada laboral $C$

trabajo necesario $A<$ trabajo necesario $C$

plustrabajo $A<$ plustrabajo $C$

El salario a destajo constituye la expresión del segundo modo de explotación hacia quienes trabajan en el área social, ligada a la creación de plusvalor relativo, el cual implica un proceso de intensificación del trabajo. En el área social, éste se caracteriza por la obtención de un salario subordinado al cumplimiento de metas que permite la sustracción de un plusvalor por parte de la burocracia estatal. Esto último llama profundamente la atención toda vez que Marx afirmó que "el pago a destajo es la forma del salario más adecuada al modo de producción capitalista" $"$.

A los bajos salarios, a los múltiples empleos parciales, y a la duración indefinida de la jornada, ahora se suma la exigencia de productos medibles sin consideración del tiempo que implica la producción de aquellos. No sólo se trabajan más horas, sino que con mayor intensidad. Como aquí el control del trabajo no es sobre la jornada sino sobre los productos, el pago a destajo ofrece un falso "sentimiento de libertad, la independencia y el autocontrol de los obreros, y por otra parte la competencia entre ellos mismos, de unos contra otros" 91 . Tanto salario por tiempo como salario a destajo contribuyen, además, a una subyugación neoliberal de quienes trabajan en el área, reforzando los valores del individualismo y la competencia. Examinadas estas dos formas de explotación, veremos a continuación, el modo en que se insertan las OSFL en este esquema.

\subsection{La acumulación capitalista: el 'lucro' de los organismos 'parásitos' desde los procesos de circulación y producción de mercancías}

Si bien el Estado saca una gran tajada a través de los incentivos al desempeño ya mencionados, la acumulación de capital es protagonizada más bien por las OSFL a quienes el Estado externaliza la política social. ¿Cómo ingresan estos organismos? Con respecto al

\footnotetext{
${ }^{90}$ Ibíd., 678.

${ }^{91}$ Ibíd., 677.
} 
salario a destajo, Marx sostiene que "como la calidad e intensidad del trabajo están controladas aquí por la forma misma del salario, ésta vuelve superflua gran parte de la vigilancia del trabajo"92. En efecto, el salario por tiempo exige que el capitalista vigile las horas destinadas a la producción de plusvalor, sin embargo, el salario a destajo no implica ese tipo de vigilancia en cuanto al cumplimiento de la jornada, sólo importa el control de los productos o metas. Aún más, no importa quién realice el trabajo, ya que no es necesario el control de la presencia y de los movimientos de quien trabaja, más bien importa que el trabajo se haga, sea quien sea que lo haga, y que se evidencie en el producto esperado. Es por ello que el salario a destajo "facilita la interposición de parásitos entre el capitalista y el obrero, el subarriendo del trabajo" "93. El Estado ya no necesita realizar por sí mismo el trabajo: puede subarrendarlo a parásitos como las OSFL $^{94}$.

Los llamados parásitos de la política social son conocidos en Chile y en el mundo a través de diversos nombres: OSFL (Organizaciones sin fines de lucro) (Bravo y León: 59), ONGs (Organizaciones No Gubernamentales) ${ }^{95}$, OCAS (Organismos Colaboradores Acreditados $)^{96}$. Existen alrededor de "450 corporaciones, ONGs, OCAs y fundaciones: 'cada una tiene de 25 a 100 trabajadores, y algunas, como Opción o Integra, varios miles" $" 97$. El dispositivo que anuda el vínculo entre el Estado y estas entidades es el llamado 'sistema de licitaciones', mediante el cual el Estado externaliza la política social, financiando económicamente a entidades específicas que postulan y ganan concursos ligados a diversos programas sociales ${ }^{98}$. Este sistema está presente casi totalmente en la implementación de la política social, por ejemplo, en la política ligada a infancia, "Sename

\footnotetext{
92 Ibíd., 674.

${ }^{93}$ Ibíd., 675.

94 Por el concepto de 'parásitos' no nos referimos a que las OSFL sean organismos prescindibles o innecesarios para el capitalismo, más bien recogemos la definición que Marx utiliza al respecto. En El capital, Marx caracteriza como 'parásitos' a: a) quienes subarriendan trabajo, b) quienes ganan dinero como intermediarios entre el capitalista y los obreros, c) quienes, siendo obreros, son encargados de contratar y pagar a auxiliares, d) quienes, siendo obreros, explotan a otros obreros (Marx, 2009, 675). Todas estas formas de definir lo parasitario son coherentes con la lógica de funcionamiento de las OSFL.

${ }^{95}$ Arredondo y Vidal, op. cit., 1; Pávez et al., op. cit., 25.

96 El Irreverente, "Federación Nacional de trabajadores y trabajadoras del área social, FENTTAS", 2016. Disponible en http://elirreverente.cl/?p=3697. La hegemonía al interior de estas entidades está compuesta por algunos organismos tales como Opción (Corporación de Oportunidad Acción Solidaria Opción), SERPAJ (Corporación Servicio Paz y Justicia), Llequén (Corporación Llequén), Protectora de la Infancia (Sociedad de Asistencia y Capacitación, antes denominada Sociedad Protectora de la Infancia), ADRA (Agencia Adventista de Desarrollo y Recursos Asistenciales), CODENI (Fundación Consejo de Defensa del Niño), Paicabí (ONG de Desarrollo, Centro de Promoción y Apoyo a la Infancia), Mi Casa (Fundación Mi Casa), Tierra de Esperanza (Fundación Tierra de Esperanza), COANIL (Fundación de Ayuda al Niño Limitado), entre otros.

${ }^{97}$ Kaos en la red, "Chile: los subcontratados del Estado”, 2015. Disponible en http://kaosenlared.net/chile-lossubcontratados-del-estado/

${ }^{98}$ El Irreverente, op. cit.
} 
sólo se hace cargo de un 5\% de los proyectos, el 95\% restante está radicado en las OCAs ${ }^{99}$, mientras SENAME administra 62 programas, las OCAs lo hacen con $1.561^{100}$.

El sistema de licitaciones, entendido como proceso de externalización de la política social de manos del Estado a privados, implica tres fenómenos claramente observables: competencia, subcontratación y lucro.

En primer lugar, la lógica de la competencia entre las OSFL por ganar los concursos públicos reemplaza la asignación de financiamiento directo a lxs trabajadores. Sin embargo, esta competencia, como vimos, es transmitida desde las OSFL a la clase trabajadora misma a través de los modos de explotación ya señalados. Por ello, cuando el sistema de licitaciones supone la competencia entre las OSFL lo que ocurre en realidad es una competencia entre lxs trabajadores propiamente tales. Veremos que las OSFL no necesitan experimentar directamente los efectos psicológicos de la competencia, cuando tienen a su disposición un capital y una fuerza de trabajo que les permiten desentenderse de la subsistencia económica.

En segundo lugar, con la interposición de tales parásitos se genera la subcontratación de quienes trabajan en el área social; ello permite que el Estado se desentienda de la responsabilidad de garantizar los derechos laborales, dejándola en manos de privados. Del total de trabajadorxs en Chile, "sólo el 26,3 \% corresponde a asalariados contratados directamente, un $41,2 \%$ a asalariados externos (subcontratados, por suministro de trabajadores y enganche) y un $30 \%$ a trabajadores por cuenta propia" ${ }^{101}$. De este grupo de asalariados externos, el 75,1\% se encuentra en los sectores 'servicios sociales y de salud' $(23,7 \%)$, 'administración pública' (7,7\%), y 'enseñanza' $(43,7 \%)^{102}$, sectores representativos del trabajo en el área social, lo cual evidencia el alto grado de subcontratación en el área. Este desentendimiento del Estado se transforma en una complicidad al posibilitar el sostenimiento de los modos de explotación ya analizados.

En tercer lugar, la externalización sostiene el llamado 'lucro en las políticas públicas' $^{103}$. En el contexto de la política social en Chile, el Estado es la mayor fuente de financiamiento de las OSFL, la cual asciende a un $46 \%{ }^{104}$. Para el caso de SENAME, en

\footnotetext{
${ }^{99}$ La Haine, "Fin al lucro en políticas sociales", 2015. Disponible en http://www.lahaine.org/mundo.php/final-lucro-en-politicas

100 The Clinic, "Los millonarios recursos que los organismos colaboradores del Sename acumulan en sus cuentas corrientes", 2016. Disponible en http://www.theclinic.cl/2016/09/14/los-millonarios-recursos-que-losorganismos-colaboradores-del-sename-acumulan-en-sus-cuentas-corrientes/

101 Fundación Sol, "Los verdaderos sueldos de Chile: panorama actual del valor del trabajo usando la Encuesta NESI", 2015, p. 6. Disponible en:

http://www.fundacionsol.cl/wp-content/uploads/2015/06/Verdaderos-Salarios-2015.pdf. Esta cifra contrasta con la entregada por el Instituto Nacional de Estadísticas, según la cual el $82,7 \%$ de la fuerza en Chile está contratada directamente con la empresa en donde trabaja. De todos modos, no deja de ser alarmante la cifra entregada por esta misma entidad con respecto al subcontrato, específicamente en el sector público, el cual asciende a un 34,8\% (Instituto Nacional de Estadísticas, Asalariados públicos y privados por tipo de relación directa o triangular según sexo. Total país. Disponible en http://www.ine.cl/estadisticas/laborales/ene).

102 Fundación Sol, "Variación de los asalariados externos por sector económico entre Enero-Marzo 2010 y Abril-Junio 2015", 2015. Disponible en: http://www.fundacionsol.cl/graficos/variacion-de-los-asalariadosexternos-por-sector- economico-entre-enero-marzo-2010-y-abril-junio-2015/.

${ }^{103}$ El Irreverente, op. cit.

${ }^{104}$ Bravo y León, op. cit., 66.
} 
2015 "se destinaron \$145 mil millones de pesos para atender a los menores en las OCAs"105 $\mathrm{y}$ ante la precariedad laboral sostenida y la ineficaz labor realizada, estas entidades acumulan en sus cuentas corrientes un total aproximado de 20 mil millones de pesos que no han sido gastados ${ }^{106}$. Estos miles de millones, SENAME los denomina 'empozamientos' y las OCAs los llaman 'saldos' ${ }^{107}$. Un dirigente sindical de estas entidades privadas afirma:

nos estaban robando 200 mil pesos de nuestros sueldos (...) [tenían] 'secuestrados' 7 millones de pesos destinados a los usuarios, y que no los gastaría en la ejecución de los proyectos (...). Un miembro del directorio, por hacer una capacitación de media hora cobra 700 mil pesos ${ }^{108}$.

Esta acumulación se justifica "con boletas falsas, trabajadores inexistentes, pagos de arriendos irreales, equipos de trabajo con menos personal del necesario"109; un dirigente sindical afirma, por ejemplo, que "un miembro del directorio adjudicó a una empresa el traslado de los equipos de trabajo. Tiempo después, los trabajadores supieron que él era el dueño de esa empresa" ${ }^{\prime 10}$.

Desde un punto de vista económico político es este tercer aspecto, el 'lucro'111, el que resulta relevante de analizar desde las categorías propuestas por Marx en El capital. Considerando las formas de explotación ya analizadas, vemos que existe un interjuego entre, por un lado, los llamados empozamientos o saldos millonarios, es decir, entre el lucro y, por otro lado, los robos, desvíos de dinero, bajos salarios e implementación precaria de los programas. Si explicamos este interjuego a través de lo que Marx denominó proceso de «circulación de mercancías» y «proceso de producción de mercancías», podremos demostrar la existencia del lucro en la política social, entendiendo éste como proceso de

105 The Clinic, op. cit.

106 Ídem.

107 Ídem.

${ }^{108}$ La Haine, op. cit.

${ }^{109}$ Kaos en la red (2015). "Chile: los subcontratados del Estado". Disponible en http://kaosenlared.net/chilelos-subcontratados-del-estado/.

${ }^{110}$ Rebelión, op. cit.

${ }^{111}$ Mientras la categoría de 'lucro' es propia de un contexto jurídico y hace referencia, en términos generales, a una ganancia económica vinculada a una práctica de abuso; las categorías de ganancia y plusvalor en $E l$ capital de Marx poseen un sentido económico diferente y mucho más preciso que no necesariamente implican un abuso jurídico, sino más bien son parte del funcionamiento legal del capitalismo. Por otro lado, las categorías de plusvalor y ganancia son diferentes en el corpus marxiano; mientras el plusvalor hace referencia al excedente de valor creado en el proceso productivo, siendo la determinación de su tasa "expresión exacta del grado de explotación de la fuerza de trabajo", a través de la razón entre plusvalor y capital variable (Marx, 2015, op. cit., 262); la ganancia es "un excedente por encima del capital global adelantado" (Marx, Karl, El capital, crítica de la economía política, Libro tercero, El proceso global de la producción capitalista, vol. 6, Siglo XXI, México, 2009, 1a edición, p. 49), siendo determinada su tasa a través de la razón entre plusvalor y dicho capital global adelantado, el cual incluye tanto al capital constante y variable. Esta distinción es fundamental para Marx, ya que es en la confusión entre ambas que los capitalistas aducen obtener mínimas ganancias, sin prestar atención la tasa de plusvalor. En lo que sigue del presente escrito sólo vincularemos y explicaremos la categoría de lucro desde la categoría de plusvalor, sin ser uno sinónimo de la otra. De este modo, pretendemos apoyar el sentido común crítico de aquellos sectores y movimientos de trabajadoras/es 'abusados' que han utilizado la categoría 'lucro', ofreciendo conexiones con categorías económicas más precisas. 
acumulación de capital. Primero veamos cómo opera el proceso global de financiamiento y ejecución de la política social, para posteriormente analizarlo desde los procesos de circulación y producción de mercancías.

El circuito (véase figura 5) comienza con el Estado, quien posee un presupuesto destinado a la ejecución de la política pública, fondos públicos que constituyen un dinero inicial (D1). Mediante el sistema de licitaciones, el Estado entrega estos fondos a las OSFL, para la ejecución de los programas sociales, lo cual constituye el primer paso de un proceso de compra-venta entre Estado y OSFL (1). Las OSFL que ganan las licitaciones se adjudican dichos fondos (D2) lo cual les permite ahora subcontratar a quienes trabajan en el área social, es decir, comprar su fuerza de trabajo (2), entendida ésta como una mercancía (M1). La clase trabajadora ha vendido su fuerza de trabajo (3), recibiendo así un salario por tiempo y a destajo (4), el cual constituye un monto de dinero (D3) con el cual ahora puede comprar nuevas mercancías (5) destinadas a su subsistencia (M2). La ejecución de los programas, en tanto mercancías (M3), se incorporan a la gama de medios de subsistencia a obtener (6), en la medida que gran parte de la política social en Chile sigue estando en manos de privados y por tanto debe pagarse por ella. La ejecución de la política pública, en tanto nueva mercancía (M3), es finalmente vendida por parte de las OSFL al Estado (7), finalizando así el proceso de compra-venta iniciado por el Estado. Esta venta se traduce en un dar cuenta de las metas logradas, y por tanto configuran una nueva mercancía (M4).

Figura 5.

Financiación e implementación de la política social en Chile como proceso de circulación de mercancías y de extracción de plusvalor

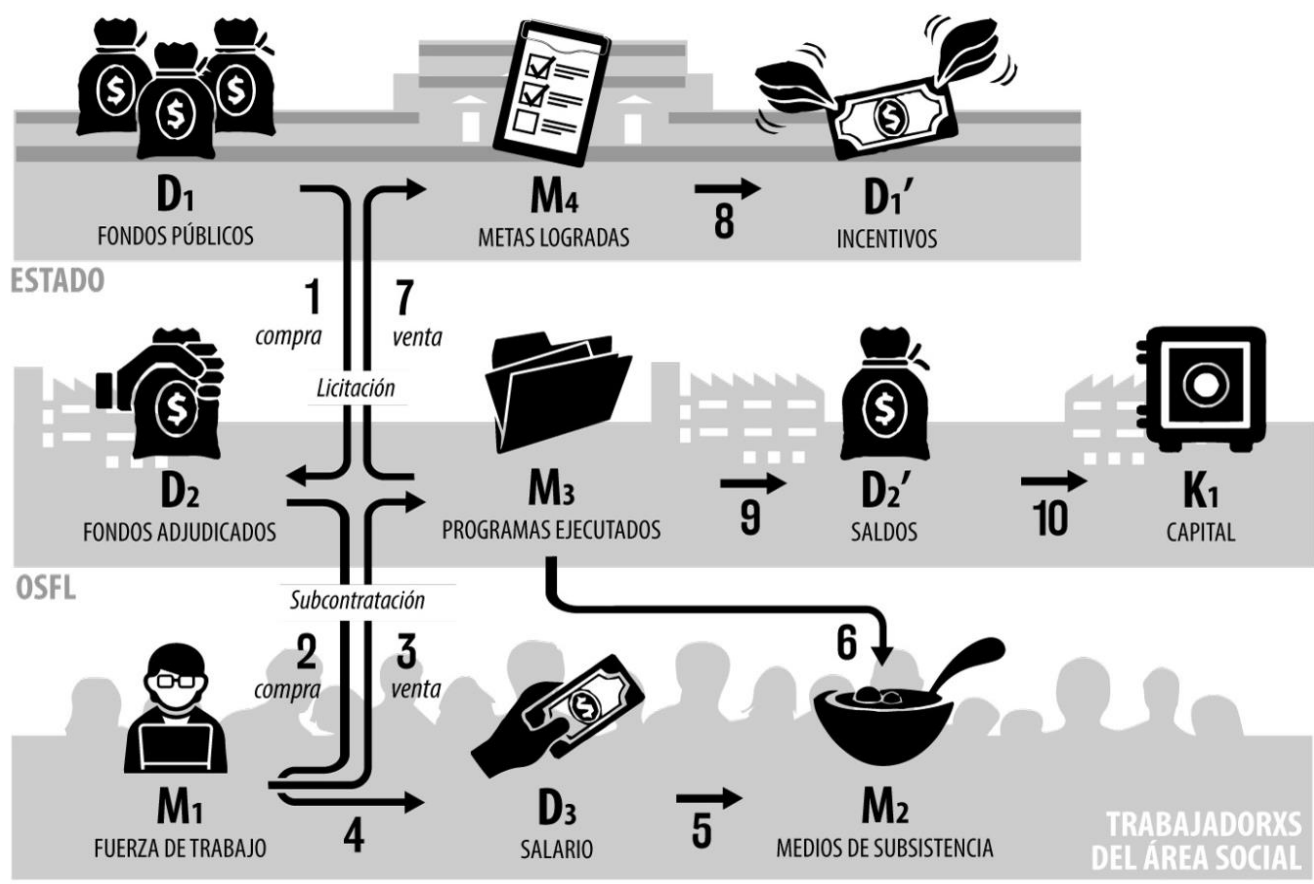


Según Marx, el proceso de circulación de mercancías se define por la fórmula M-DM, lo cual implica la venta de una mercancía (M) por dinero y, con dicho dinero, la compra de otra mercancía diferente $(\mathrm{M})^{112}$. Ahora bien, en la medida que el dinero se ha transformado en sí mismo en una mercancía a obtener en un modo de producción capitalista, emerge la fórmula general del capital, D-M-D. Esta fórmula invertida, señala al dinero al inicio (D) con el cual se compra una mercancía (M), la cual es vendida nuevamente para obtener dinero (D). Según Marx: "El dinero que en su movimiento se ajusta a ese último tipo de circulación, se transforma en capital y es ya conforme a su determinación, capital"113. Esto debido a que la forma plena de este segundo tipo de circulación "es, por ende, D-M-D', donde $\mathrm{D}$ ' $=\mathrm{D}+\Delta \mathrm{D}$, esto es igual a la suma de dinero adelantada inicialmente más un incremento" ${ }^{114}$, el cual, como ya hemos visto, Marx denomina plusvalor. Este segundo tipo de circulación "modifica su magnitud de valor, adiciona un plusvalor o se valoriza. Y este movimiento lo transforma en capital" 115 . De este modo es posible observar cómo, desde el punto de vista de la circulación, la venta de la ejecución de los programas sociales (3), en tanto mercancía (M3) genera un monto de dinero excedente ( 8 y 9 ), el cual se expresa tanto en los empozamientos millonarios de las OSFL (D1') como en los incentivos a los logros por desempeño del Estado (D2').

Ahora bien, Marx plantea que "la formación de plusvalor y, por consiguiente, la transformación del dinero en capital, no pueden explicarse ni porque los vendedores enajenen las mercancías por encima de su valor, ni porque los compradores las adquieran por debajo de su valor" 116 . Es por ello que se hace necesario analizar el proceso de producción de mercancías ${ }^{117}$, el cual "no es más que el consumo de la mercancía fuerza de trabajo"118, a través del cual el capitalista busca "producir una mercancía cuyo valor sea mayor que la suma de los valores de las mercancías requeridas para su producción"119. La fuerza de trabajo, al diferenciarse de todas las demás mercancías por su capacidad de crear valor $^{120}$, permite entonces la creación de plusvalor y la acumulación de capital. Esto nos permite comprender que, desde el punto de vista de la producción, los excedentes generados en la financiación y ejecución de la política social (D1' y D2') se generan a través de la explotación de la fuerza de trabajo de la clase trabajadora del área social (M1).

\footnotetext{
${ }^{112}$ Marx, 2008, op. cit., 129.

113 Ibíd., 180.

${ }^{114}$ Ibíd., 184.

115 Ibíd., 196.

116 Ibíd., 196.

${ }^{117}$ Esto es relevante ya que, si bien nos proponemos analizar la explotación en el área social desde una matriz conceptual propia del proceso de circulación de mercancías, no deseamos sostener la tesis de que existe una explotación mediante la esfera de la circulación (tesis sostenida por economistas como Paul Sweezy y Paul Baran). Más bien, como plantea Marx, lo que puede observarse en el proceso de circulación debe ser explicado desde lo que ocurre en el proceso de producción. No obstante, debido al carácter exploratorio de este escrito, hemos decidido ocupar adicionalmente formulaciones propias de la esfera de la circulación; quedando como desafío para futuras investigaciones desentrañar la explotación desde categorías que se articulen de manera mucho más directa con la esfera de la producción.

118 Ibíd., 225.

119 Ibíd., 226.

${ }^{120}$ Ibíd., 215.
} 
En la medida en que el Estado y las OSFL generan este plusvalor a través de la forma D-M-D (específicamente D1-M4-D1' para el caso del Estado y D2-M3-D2' para el caso de las OSFL), éstas se ajustan a la expresión 'comprar para vender', lo cual implica según Marx la existencia de un proceso de acumulación de capital ${ }^{121}$. Aquí, son las OSFL quienes acumulan capital $(10, \mathrm{~K} 1)$, ya que, si bien el Estado sustrae un incentivo que no le corresponde, no es capaz de reproducir una acumulación de capital toda vez que subsiste como Estado capitalista. En este sentido, si bien aquí el Estado no obtiene los beneficios de un capitalista, sí actúa como tal, al participar del esquema D-M-D, colaborando con las OSFL. Mientras tanto, la clase trabajadora participa del circuito inverso M-D-M (específicamente M1-D3-M2), sólo destinado a la reproducción de la fuerza de trabajo mediante la obtención de medios de subsistencia.

La inversión de la fórmula M-D-M en D-M-D, en la esfera de la circulación y la sustracción de plusvalor por parte de las OSFL y el Estado en la esfera de la producción, no sólo nos muestran la estructura que sostiene la explotación de la clase trabajadora del área social, sino, además, el rol capitalista que no sólo poseen las OSFL sino incluso el Estado. Dicha acumulación de capital explica el denominado 'lucro' en el área social.

\section{Conclusión}

A lo largo de este recorrido hemos visto dos formas mediante las cuales se explota a quienes trabajan en el área social en el Chile actual. En el caso de la producción de plusvalor absoluto, vimos como la temporalidad limitada del trabajo (jornada parcial, inestabilidad laboral), sustenta un pago de salarios por debajo de lo equivalente al trabajo necesario para la subsistencia de la clase trabajadora, lo cual obliga la búsqueda de otras fuentes de ingreso que prolongan la jornada laboral y por tanto generan un descenso en el valor del salario medio. En el caso de la producción de plusvalor relativo, hemos visto como la exigencia de metas en el trabajo permite la obtención de plusvalor en la clase burócrata y la intensificación de la labor de la clase trabajadora en una misma jornada laboral, sumando a ello la inserción de 'parásitos', las OSFL, que lucran con fondos públicos. Por último, vimos cómo este lucro se reproduce siguiendo el esquema D-M-D' propuesto por Marx, que implica la producción y venta de una mercancía por parte de estas entidades que es comprada por el Estado, lo cual genera un plusvalor y un capital. De este modo hemos analizado el trabajo en el área social en el contexto del capitalismo chileno, al auxilio de conceptos fundamentales propuestos por Marx comprobando además la vigencia de aquellos en la actualidad.

Frente a estos modos de explotación, emergen algunas posibles propuestas que se desprenden inmediatamente del diagnóstico realizado: a) salarios que permitan no sólo la subsistencia de quienes trabajan en el área sino que además reconozcan el carácter de la labor, b) la limitación de la prolongación de la jornada laboral, ya sea evitando la coexistencia de múltiples jornadas parciales o asegurando la estabilidad laboral ${ }^{122}$, c) la

\footnotetext{
${ }^{121}$ Marx, 2008, op. cit., 180.

122 Con la proposición de una medida como esta no asumimos que a mayor regulación del trabajo existe necesariamente un mejoramiento de las condiciones de la clase trabajadora, ya que dicha regulación puede
} 
erradicación del salario basado en metas, logros o desempeño, d) la fiscalización de la labor actual del Estado y el uso de los recursos, y e) la erradicación de los organismos privados en la ejecución de la política social, lo cual implica a su vez, el fin del sistema de licitaciones y del lucro en el área social. Esta última medida, la cual ha sido propuesta por FENTTAS (Federación Nacional de Trabajadoras/es del Área Social) ${ }^{123}$ abre la puerta para un nuevo sistema, lo cual no implica sólo una discusión amplia en torno a la forma en que la clase trabajadora desea financiar y ejecutar las políticas sociales, sino además implica un nuevo papel protagónico de esta clase en la toma de decisiones respecto al rol del Estado, cuestionando su rol en el capitalismo. Con respecto a este último punto, se hace relevante la sentencia de Meiksins Wood, al plantear que

Aun cuando, como ahora parece posible, la actual crisis global ponga un freno a la globalización neoliberal, la misma no terminará con la universalización del capitalismo y las crecientes contradicciones que resultan de ella, y el capital seguirá necesitando la ayuda del estado para navegar las turbulentas aguas de la economía global ${ }^{124}$.

Para avanzar en esta lucha, en el contexto del área social en Chile, sigue siendo relevante lo que ya Marx planteara para la clase trabajadora en su conjunto. Ello exige el reconocerse como trabajadorxs y no como 'prestadorxs de servicio' o meros 'profesionales', y como parte de una clase explotada colectivamente por extensas empresas sociales a nivel nacional. Se hace necesario continuar denunciando en este sector la complicidad entre Estado y OSFL en el sostenimiento de este modo de producción, así también generar asociaciones con otros sectores que viven dicha precariedad de formas similares, ya sea tanto en sector privado como en el público ${ }^{125}$. En este sentido, la lucha contra el sistema de licitaciones en el área social debe articularse con luchas similares, como aquellas que exigen acabar con el subcontrato y el contrato honorarios, entre otras. La organización de este sector debe, además, considerar las luchas ya libradas anteriormente, aprender de éstas y reorientar sus tácticas para no ceder, por un lado, ante las OSFL cuando éstas amenacen con lanzarnos a su ejército de reserva, y por otro, ante las trampas estatales,

\footnotetext{
justamente servir para sostener de mejor forma, desde un punto de vista jurídico, la economía capitalista, independiente de si aquella regulación proviene por parte del Estado o de las empresas. Más bien, una propuesta como esta debe ser leída desde un punto de vista crítico. Tal como señala Ellen Meiksins Wood, "'Globalization' -in particular, the withdrawal of the state from regulatory and social welfare functions in the interests of capital mobility and 'competitiveness' in the world market- is the product of policy choices, not the working out of natural laws, not even the inevitable destination of history - however much these policies have spread from neoliberalism across the whole political spectrum" (Meiksins Wood, E., "Modernity, postmodernity or capitalism?", Review of international political economy, 1997, 4:3, 558).

${ }^{123}$ El Irreverente, op. cit.

${ }^{124}$ Meiksins Wood, E. "Trabajo, clase y Estado en el capitalismo global”, en Meiksins Wood, E., Meiksins, P., Yates, Michael D., Rising from the ashes?: labor in the age of "global" capitalism, Monthly Review Press, 1998, trad. de Florencia Enghel, revisión técnica de Atilio A. Borón, p. 84.

125 En torno a esto, cobra relevancia la organización y movilización las/os trabajadoras/es a honorarios del Estado de Chile, durante entre los años 2013-2015. Para mayor información sobre este sector específico véase Arredondo, Félix, "Los trabajadores a honorarios como una arista de la modernización del Estado", Cuadernos de coyuntura, Nodo XXI, n. 9, invierno, 2015, Santiago.
} 
a las migajas del reformismo o al reduccionismo legalista, que termina cooptando la organización obrera al interior del aparato burócrata.

Por último, el desarrollo de una lucha de clases desde el área social hace necesaria la conexión con horizontes o proyectos de transformación política mucho más amplios, ante lo cual Marx algo nos susurra en El capital: "imaginémonos finalmente, para variar, una asociación de [personas] libres que trabajen con medios de producción colectivos y empleen, conscientemente, sus muchas fuerzas de trabajo individuales como una fuerza de trabajo social (...)"126. Ello nos lleva a cuestionar no sólo la presencia de privados en la política social, sino del mismo Estado como instrumento de la clase burguesa y en sí misma como clase dominante. Las formas concretas de materializar un horizonte de este tipo quedan abiertas; por el momento nos queda luchar contra la explotación tanto en el área social como en otras áreas de la vida.

\section{Referencias bibliográficas}

\section{Libros y artículos}

Antúnes, Ricardo (2001). ¿Adiós al trabajo? Ensayo sobre las metamorfosis y la centralidad del mundo del trabajo, Biblioteca Latinoamericana de Servicio Social, Sao Paulo.

Arredondo, Félix; Vidal, Paula (2013). "Trabajadores del área social. El estado en cuestión", Ponencia presentada en el XXIX Congreso de la Asociación Latinoamericana de Sociología. Chile. $2013 . \quad$ Disponible en: http://actacientifica.servicioit.cl/biblioteca/gt/GT18/GT18_Arredondo_Vidal.pdf

Arredondo, Félix (2015). "Los trabajadores a honorarios como una arista de la modernización del Estado", Cuadernos de coyuntura, Nodo XXI, n. 9, invierno, Santiago.

Bhaduri, Amit \& Robinson, Joan (1980). "Accumulation and exploitation: an analysis in the tradition of Marx, Srafia and Kalecki", Cambridge Journal of Economies, 4, 103-115.

Bravo, Francisco; León, Beatriz (2016). "Precariedad Laboral: el caso de los trabajadores del Área Social”, Tesis para optar al grado de Licenciado/a en Trabajo Social, Tesis para optar al título de Asistente Social, Universidad Academia de Humanismo Cristiano, Santiago de Chile. Disponible

en: http://bibliotecadigital.academia.cl/bitstream/handle/123456789/3839/TTRASO\%20487.pdf

Brewer, J. (1987). "Exploitation in the new Marxism of collective action". The Sociological Review, 35: 84-96.

Cornejo, Miguel (2009). "Gestión Pública, Incentivos y Remuneraciones en Chile”, Revista de estudios politécnicos, vol VII, n. 11: 1-15. Disponible en: http://www.scielo.mec.pt/pdf/tek/n11/n11a05.pdf

Holmstrom, Nancy, (1977). "Exploitation", Canadian journal of philosophy, Volume VII, Number 2 , june.

Kliman, A. (2011). The failure of capitalist production. Underlying causes of great recession, Pluto Press.

Madrid, Patricio (2013). "Un análisis a la efectividad del uso de incentivos al desempeño en el sector público”, Seminario para optar al Título de Ingeniería Comercial, Mención Economía,

${ }^{126}$ Marx, 2008, op. cit., 97. 
Universidad de Chile, Santiago de Chile. Disponible en: http://repositorio.uchile.cl/handle/2250/112133

Marx, Karl (2008). El capital, crítica de la economía política, Libro primero, El proceso de producción de capital, vol. I, Siglo XXI, México, 1a edición.

Marx, Karl (2009). El capital, crítica de la economía política, Libro primero, El proceso de producción de capital, vol. II, Siglo XXI, México, 1a edición.

Marx, Karl (2009). El capital, crítica de la economía política, Libro tercero, El proceso global de la producción capitalista, vol. 6, Siglo XXI, México, 2009, 1a edición.

Maslach, Christina y Susan Jackson (1981). MBI: Maslach Burnout Inventory. Manual. Palo Alto, California: University of California, Consulting Psychologists Press.

Meiksins Wood, E. (1995). Democracy against capitalism. Renewing historical materialism, Cambridge University Press.

Meiksins Wood, Ellen (1997). "Modernity, postmodernity or capitalism?", Review of International Political Economy, 4:3, 539-560.

Meiksins Wood, E. (1998). "Trabajo, clase y Estado en el capitalismo global", en Meiksins Wood, E., Meiksins, P., Yates, Michael D. (1998). Rising from the ashes?: labor in the age of "global" capitalism, Monthly Review Press, trad. de Florencia Enghel, revisión técnica de Atilio A. Borón, p. 84.

Meiksins Wood, E. (2005). Empire of capital, Verso.

Pascual, M. (2007). "Chile: ¿más cerca o más lejos del trabajo decente?" En Le Monde Diplomatique, El trabajo (pp. 7-18). Santiago: Editorial Aún creemos en los sueños.

Pávez, Javiera; Carrasco, Claudia; Peña, Teresa; Bilbao, Ma. Ángeles; Oriol, Xavier; Ortúzar, Harry; Rubio, Andrés; Torres, Javier (2016). "Sujeto/a trabajador/a en la política pública de intervención psicosocial de infancia en Chile: un análisis crítico del discurso", Revista de estudios cotidianos, 4(1): 23-45. Disponible en: https://dialnet.unirioja.es/servlet/articulo?codigo $=5568032$

Roemer, John E., (1982a). A general theory of exploitation and class, Harvard University Press.

Roemer, J. (1982b). "Exploitation, Alternatives and Socialism". The Economic Journal, 92(365), 87-107.

Roemer, J. (1982c). "New directions in the Marxian Theory of exploitation and class", Politics \& Society, September 1, Volume: 11 issue: 3, page(s): 253-287.

Shaikh, A. (1980). "Marxian competition versus perfect competition: further comments on the socalled choice of technique", The Cambridge journal of economics, 1980, n. 4, 75-83.

Shaikh, A. (1988). "The economic mythology of neoliberalism", en Saad-Filho, A. (ed.), NeoLiberalism: a critical reader, Pluto Press, London

Shaikh, A. (2003). "Who pays for the 'Welfare' in the Welfare State? A multicountry study", Social research, vol. 70, n. 2.

Shaikh, A. \& Tonak, E. (1987). "The Welfare State and the Myth of the Social Wagewith", en Cherry, R. et al., The imperiled economy, Book I, Union for Radical Political Economics.

Tello, Felipe (2011). "La política de reforma y modernización de la gestión pública en Chile. Actores y procesos", Universium, 26(2): 245-265, https://doi.org/10.4067/S0718 23762011000200012

Wolff, Johnatan, (1999). "Marx and explotaition", The Journal of Ethics 3: 105-120, 1999.

Wright, Erik Olin, (1988). "Exploitation, identity, and class structure: a reply to my critics", Critical Sociology, 15. 1, pp. 91-110.

\section{Documentos públicos}


Gobierno de Chile (2016). "Informe Comisión Especial Investigadora de la forma en que las autoridades han atendido las propuestas de la Cámara de Diputados, por la aprobación del Informe de la Comisión Investigadora del SENAME en el año 2014, y la situación de menores de edad carentes de cuidado parental".

Gobierno de Chile, Dirección del Trabajo (2017a). “¿Cuáles son los derechos de las personas contratadas a honorarios?”. Disponible en http://www.dt.gob.cl/consultas/1613/w3-article60764.html

Gobierno de Chile, Dirección del Trabajo (2017b). Código del Trabajo (julio de 2017). Disponible en: http://www.dt.gob.cl/legislacion/1611/articles-95516_recurso_2.pdf

Gobierno de Chile, Dirección del Trabajo (2017c). "¿Puede renovarse un contrato por obra o faena?", Disponible en http://www.dt.gob.cl/consultas/1613/w3-article-67706.html

\section{Fuentes electrónicas o digitalizadas}

24 horas (2016). "Sename, Registro Civil y Gendarmería aparecen con índices de excelencia". Disponible en http://www.24horas.cl/nacional/sename-registro-civil-y-gendarmeria-aparecencon-indices-de-excelencia-2184075

El Irreverente (2016). "Federación Nacional de trabajadores y trabajadoras del área social, FENTTAS". Disponible en http://elirreverente.cl/?p=3697

ER (2016). "The Gig Economy: Capitalism's New Normal”, Disponible en: http://www.leftcom.org/en/articles/2016-10-21/the-gig-economy-capitalism's-new-normal.

Fundación Sol (2015a). "Informe mensual de calidad de empleo (IMCE. Análisis de los microdatos liberados el 30 de Septiembre de 2015 correspondiente al trimestre móvil Junio-Agosto 2015, Informe nacional". Disponible en: http://www.fundacionsol.cl/wpcontent/uploads/2015/10/14-IMCE-JJA2015.pdf

Fundación Sol (2015b). "Los verdaderos sueldos de Chile: panorama actual del valor del trabajo usando la Encuesta NESI". Disponible en: http://www.fundacionsol.cl/wpcontent/uploads/2015/06/Verdaderos-Salarios-2015.pdf

Fundación Sol (2015c). "Variación de los asalariados externos por sector económico entre EneroMarzo 2010 y Abril-Junio 2015”. Disponible en: http://www.fundacionsol.cl/graficos/variacion-de-los-asalariados-externos-por-sectoreconomico-entre-enero-marzo-2010-y-abril-junio-2015/

Instituto Nacional de Estadísticas, Asalariados públicos y privados por tipo de relación directa o triangular según sexo. Total país. Disponible en http://www.ine.cl/estadisticas/laborales/ene

Instituto Nacional de Estadísticas, Banco de datos de la Encuesta Nacional de Empleo. Disponible en: http://bancodatosene.ine.cl

Instituto Nacional de Estadísticas, Empleo Trimestral, boletín informativo del Instituto Nacional de Estadísticas, edición n. 201, 31 de julio de 2015.

Instituto Nacional de Estadísticas, VII Encuesta de presupuestos familiares. Resultados VII EPF, septiembre de 2013. Disponible en: http://www.ine.cl/estadisticas/ingresos-y-gastos/vii-epfresultados

Kaos en la red (2015). "Chile: los subcontratados del Estado". Disponible en http://kaosenlared.net/chile-los-subcontratados-del-estado/

La Haine (2015). "Fin al lucro en políticas sociales". Disponible en http://www.lahaine.org/mundo.php/fin-al-lucro-en-politicas

La Nación, "La precariedad laboral, el lado oscuro de la exitosa política económica de Merkel". Disponible en: http://www.lanacion.com.ar/2065675-la-precariedad-laboral-el-lado-oscurode-la-exitosa-politica-economica-de-merkel. 
Rebelión (2015). "Campaña de trabajadores del área social: fin al lucro en políticas públicas". Disponible en http://www.rebelion.org/noticia.php?id=204317

Solidaridad (2016). "Nace FENTTAS, herramienta de lucha de las y los trabajadores del área social". Disponible en http://www.periodico-solidaridad.cl/2016/07/21/nace-fenttasherramienta-de-lucha-de-las-y-los-trabajadores-del-area-social/

The Clinic (2016). "Los millonarios recursos que los organismos colaboradores del Sename acumulan en sus cuentas corrientes". Disponible en http://www.theclinic.cl/2016/09/14/losmillonarios-recursos-que-los-organismos-colaboradores-del-sename-acumulan-en-suscuentas-corrientes/ 